\title{
Oilfield Production Surveillance as a Management Tool for Environmental Monitoring
}

\author{
${ }^{1}$ AJIENKA, J A; ${ }^{2}$ KUYE, A \\ ${ }^{I}$ Department of Petroleum Engineering, University of Port Harcourt, \\ PMB 5323, Port Harcourt, Nigeria \\ ${ }^{2}$ Department of Chemical Engineering, University of Port Harcourt, \\ Port Harcourt, Nigeria.Email: aokuye@enguniport.org
}

\begin{abstract}
Oilfield production surveillance is the effective monitoring of petroleum reservoirs, producing wells, flow station facilities and flow lines. Through surveillance, the production of unwanted effluents (formation water, excess gas, etc.) can be controlled. Production problems such as sand production, emulsion, corrosion, scale formation and wax blockage can lead to disposal problems and poor integrity of facilities and consequent financial losses. This paper presents a system approach for carrying out oilfield production surveillance process. Using case studies it is shown that the process can be used to identify unfavourable conditions such as gas leaks, corrosivity, and unsafe wells. It is further recommended that the frequency of surveillance should be monthly. JASEM
\end{abstract}

Environmental monitoring methods include health risk assessment and surveillance, baseline exposure evaluation, visual inspection, plant and equipment performance evaluation, process audit, etc. From our experience in Nigeria, it would appear that only the health risk assessment is emphasized in almost all the environmental impact assessment (EIA) reports. Of course, the health of personnel and those in the nearby communities are very important. However, we are of the view that equal emphasis should be placed on the use of appropriate engineering controls. Oilfield surveillance is one of the tools for choosing relevant controls.

In general, the key strategies for waste management include (a) reducing or minimizing waste generation, (b) recycling the waste and (c) reusing the waste. The objective of oilfield surveillance is to minimize waste generation through systematic monitoring of the production process. Production wastes are mainly effluent water measured in terms of basic sediment and water (BSW), excess gas production measured in terms of Gas-Oil-Ratio (GOR) and sand cut. The effluent water, apart from disposal which is an environmental problem, causes emulsion, corrosion and scale problems. Excess gas production can lead to pressure-related and vibration problems. Sand erodes facilities and causes severe damage. This paper discusses how to monitor and minimize the environmental impact of production activities in the E\&P operations using oilfield surveillance as the main tool.

\section{THE SURVEILLANCE PROCESS}

The surveillance process involves diagnosing production and facilities problems in a proactive manner before severe damage is done to equipment, personnel and environment. With an effective surveillance process in place, pollution problems such as was the case with Obelle fires (Ajienka and Kuye, 1999) will be avoided. Effective surveillance presumes that the field is well known. Also, a proper

balance must be made between producing at minimum cost and minimizing environmental impact. Allen and Roberts (1982) discussed some routines that can be used to handle well problems.

The surveillance process is shown in Fig 1. Every reservoir, every well and every facility is monitored as an entity. Once a problem is identified, tests and/or observations are carried out to ascertain the cause(s). Appropriate remedies are then put in place. After this, it will be necessary to evaluate the effectiveness of the remedies. In some cases, it may be necessary to carry out further tests/observations as can be seen in Fig 1. The outcome of a surveillance process is the report.

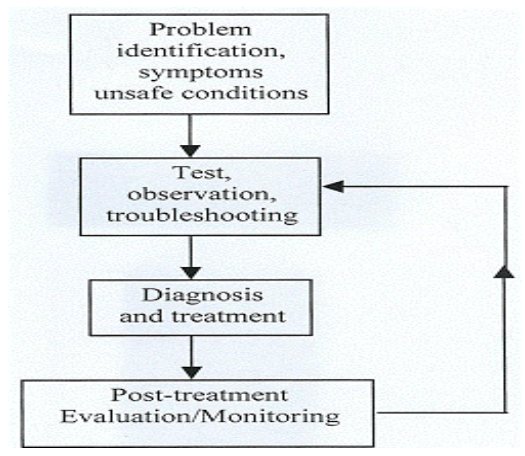

Ideally, the frequency of the surveillance is monthly. The monthly surveillance report should comprise:

(a)

In practice, most producing companies mainly concentrate on monthly well surveillance. However, experience has shown that it is necessary to carry out monthly surveillance of the other parameters 
mentioned above. Each of these aspects is discussed further in the remaining sections of this paper.

Reservoir Surveillance: The rate of reservoir pressure decline may have direct impact on productivity and environmental quality. If the reservoir pressure depletes rapidly, it will result in high gas production and water cut. These are production wastes; the disposal of which affects the environment. High pressure drop around the well bore can also cause sand production. Consequently, it is necessary to determine the predominant reservoir drive mechanism and arrest rapid pressure decline. A good pressure maintenance plan will go a long way in ensuring that this objective is achieved.

Well Surveillance: The production problems that have severe environmental impact potential are:

(a) Well producing at high Gas-Oil-Ratio (HGOR). Usually, a well is said to produce at HGOR if producing GOR is greater or equal to three times the initial solution GOR (Rsi). This implies wasting reservoir energy that can be used to produce the reservoir. It may also mean wasting the produced gas if there are no facilities for associated gas gathering (AGG) and utilization. Fig 2 gives a flow chart for diagnosing HGOR (Ajienka, 1995)

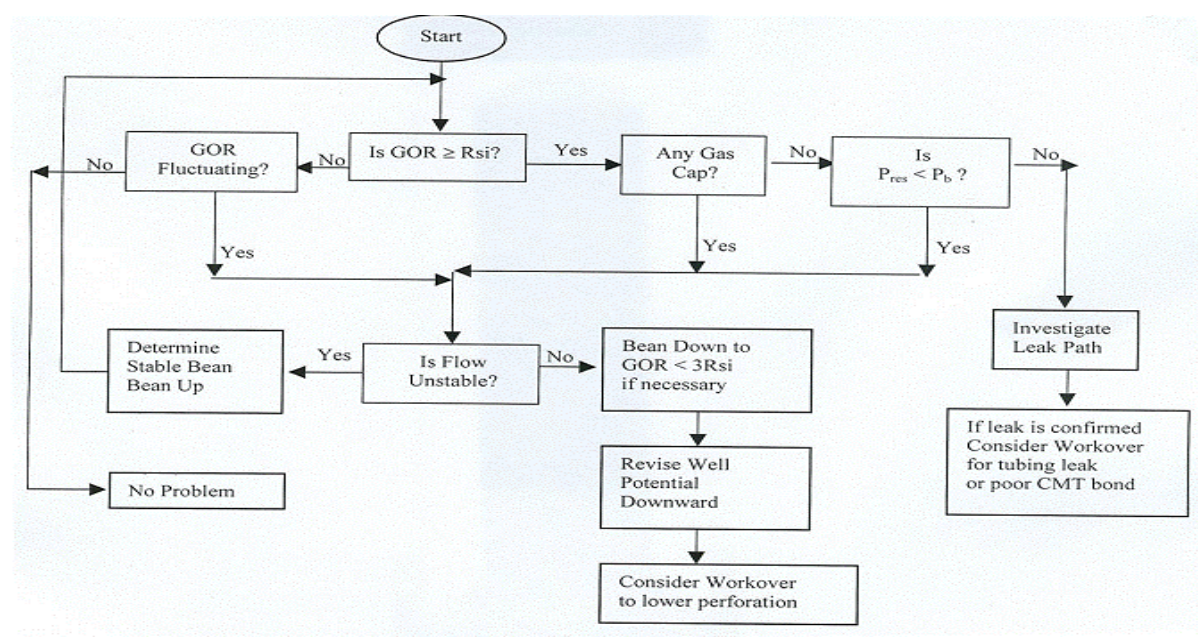

Fig 2. Flow chart for well producing at high HGOR

Wells producing at high basic sediment and water (HBSW) greater than or equal to $50 \%$. When this is the case the well experiences water loading of vertical conduit and therefore inhibits flow. Apart from this, other problems include disposal of formation water, high transportation cost and pipeline ullage problems. Fig 3 gives a flow chart for monitoring HBSW. 


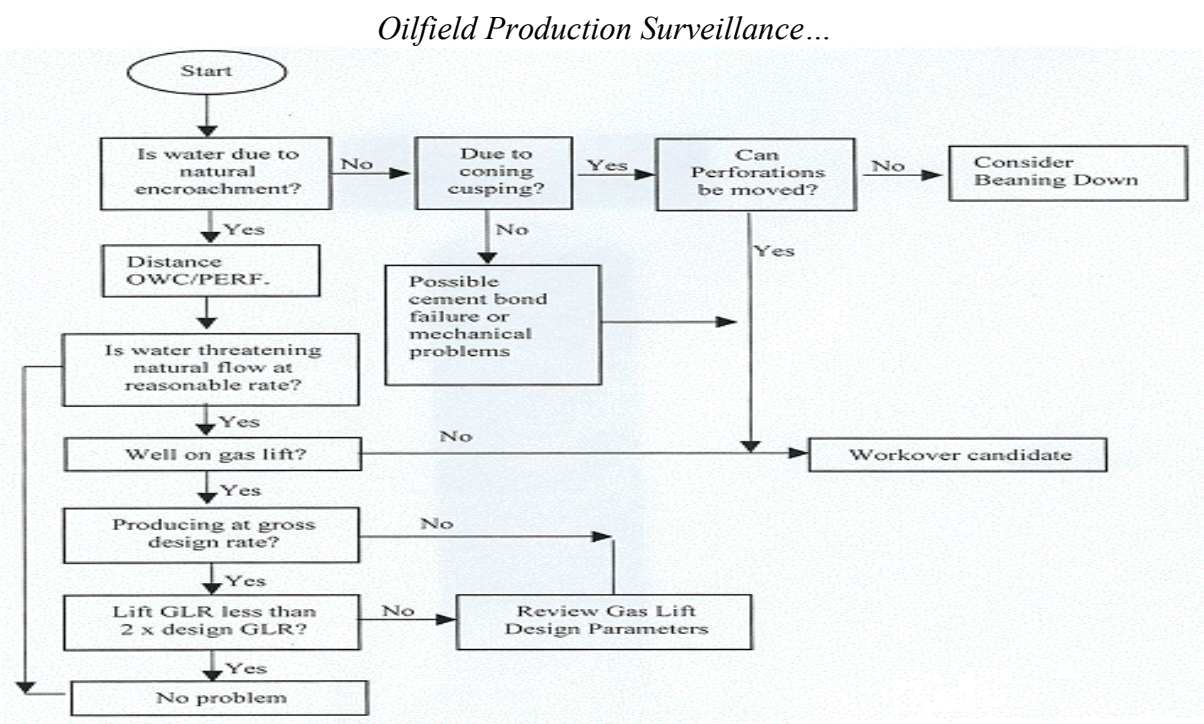

(c) Wells with sand cut greater than or equal to $10 \mathrm{lb} / \mathrm{mbbl}$. Fig 4 illustrates a process that can be used to monitor high sand cut. Sand production is a very serious services problem as it can lead to erosion and failure of facilities. It is necessary to monitor the level of the reservoir pressure drop at the well bore since high pressure drop can lead to sand failure.

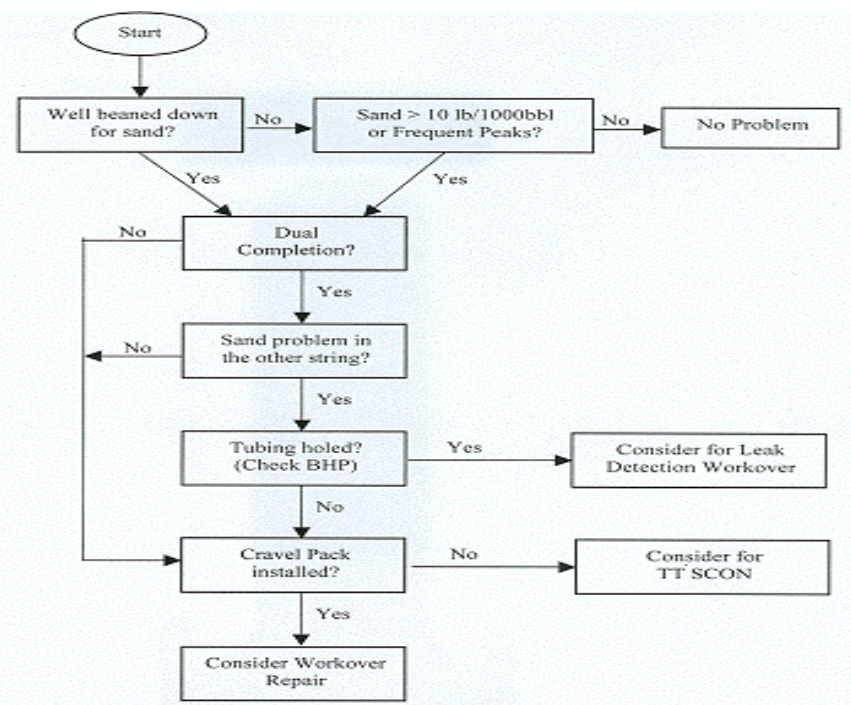

Fig 4. Flow chart for well intervals with sand problems

(d) Other problems include scale formation, corrosivity, unsafe well condition and communication between tubings. Scale formation can lead to reduced well integrity problem. Unsafe wells and communication between tubings are discussed further by Ajienka and Kuye (1999). These problems should be given prominence when carrying out well surveillance.

Flowstation Surveillance: This involves careful monitoring of parameters such as pressure (Fig 5), surge vessels (Fig 6), sand production (Fig 7), gas flaring (Fig 8), corrosion and scaling (Fig 9) and vibration (Fig 10). It should be noted that the major difference between the surveillance that is being suggested here and the usual routine monitoring of facilities, controls, etc is in the reporting of deviations from normal operation. By using Figs 5 10 , deviations and the remedies proffered should be properly documented. Such reports should be prepared on a monthly basis. 


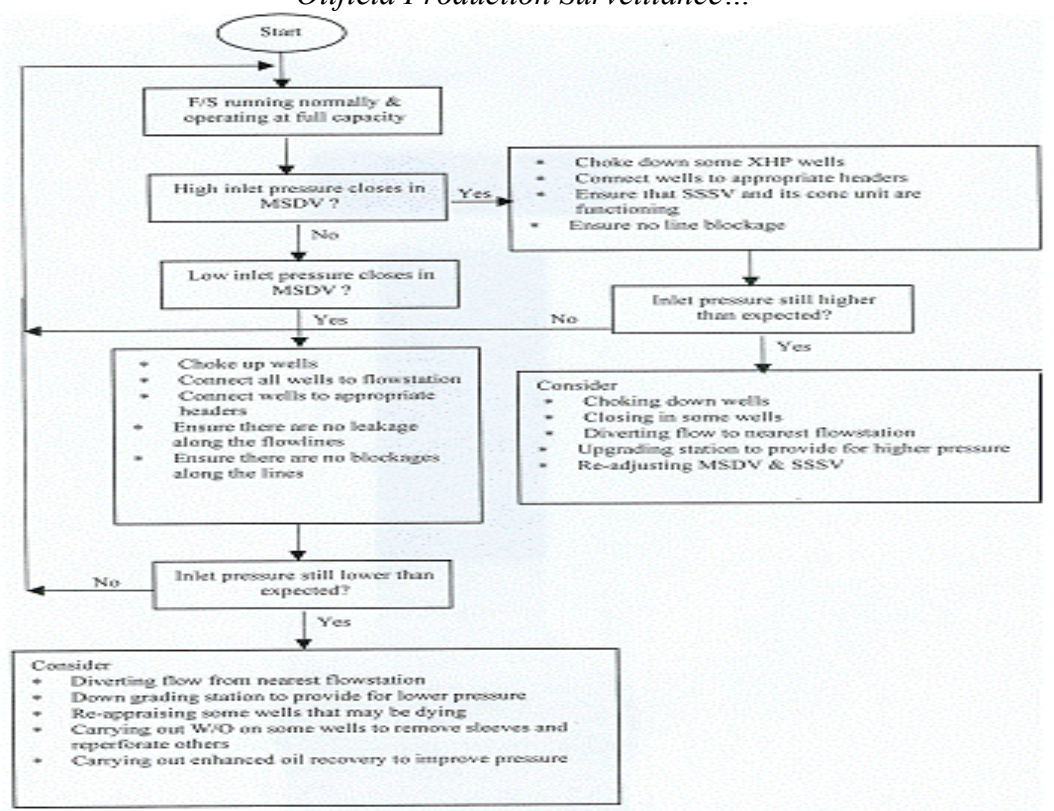

Fig 5. Flow chart for pressure surveillance

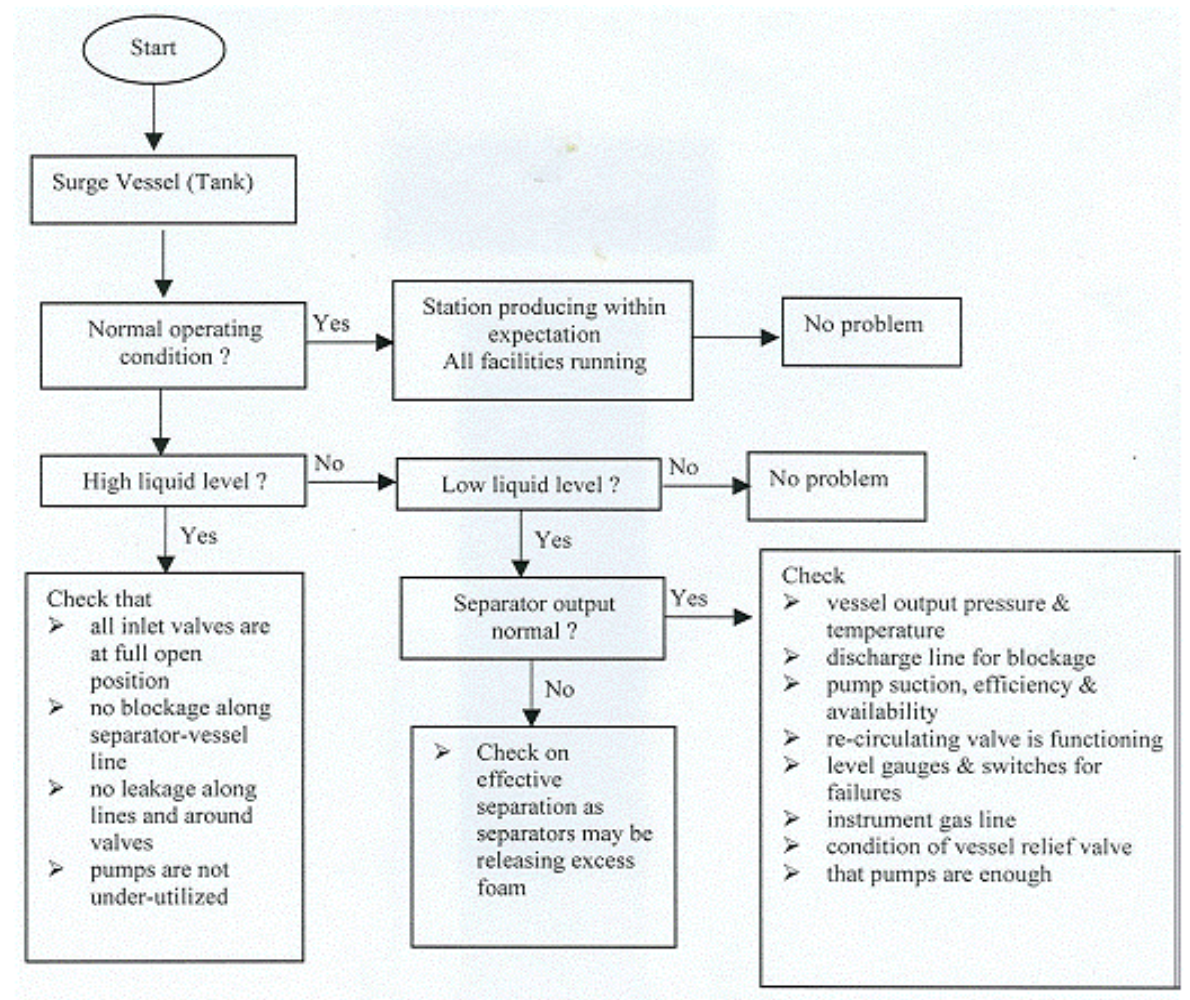

Fig 6. Surge vessel performance surveillance 


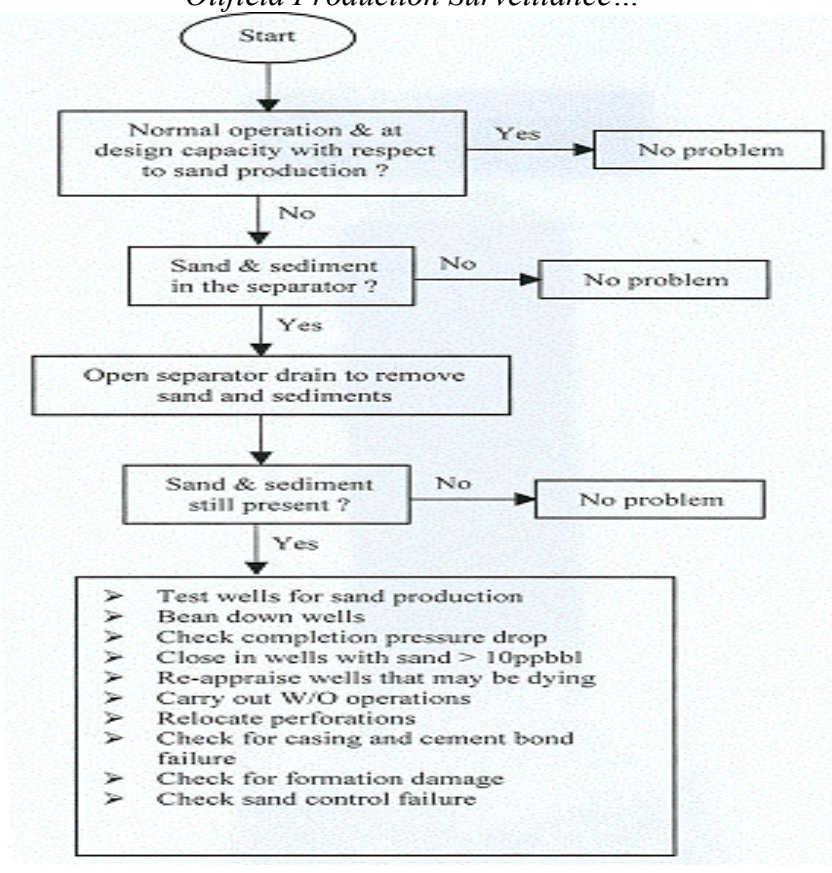

Fig 7. Surveillance for sand production from flow stations

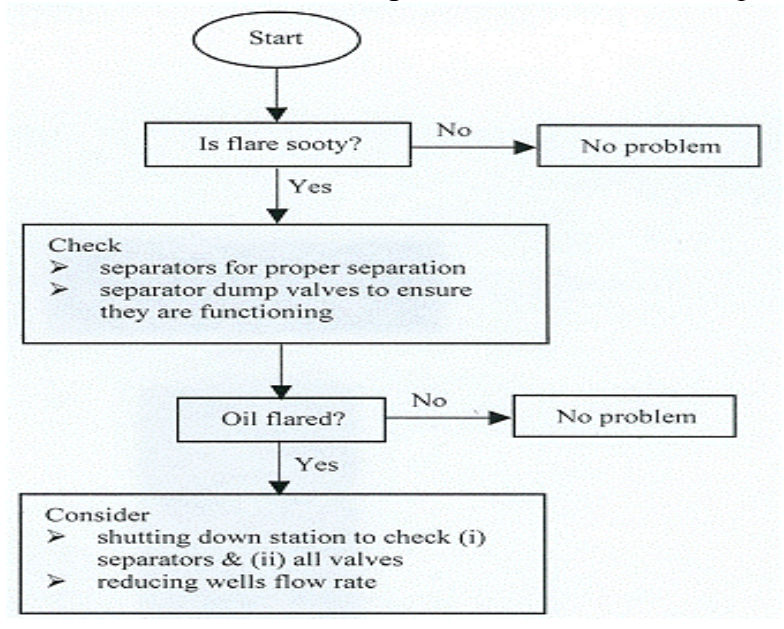

Fig 8. Surveillance for gas flares from flowstations

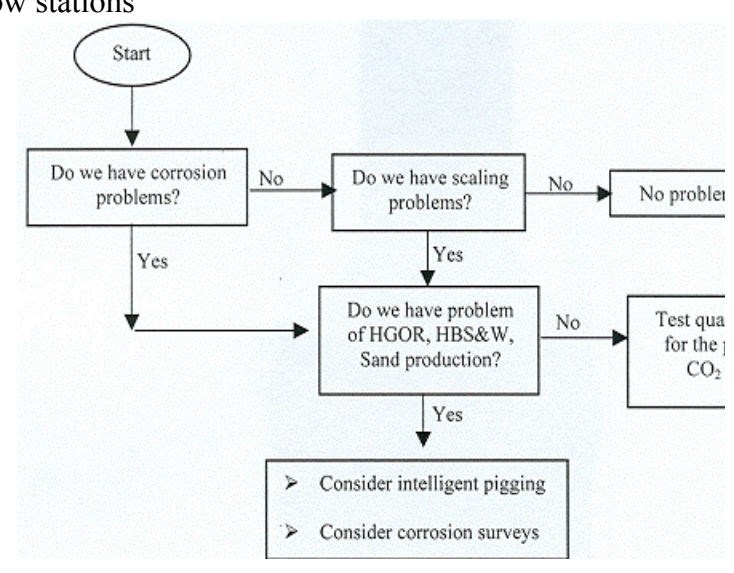

Fig 9. Surveillance for Corrosion and Scaling 


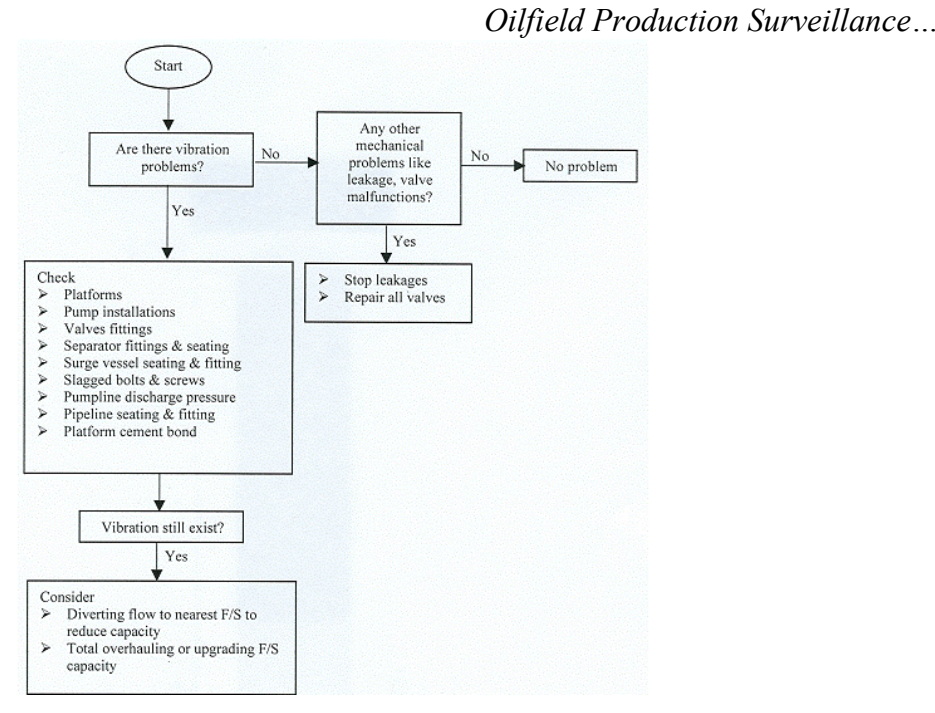

Flowline Surveillance: This is the monthly monitoring of flowlines for problems which may either block or rupture the lines. These problems include scale formation, wax deposition, corrosion and leakages. Some of the flowcharts given for flowstation surveillance can also be used for flowline surveillance. The effectiveness of flowline corrosion protection system should be carefully monitored. Regular intelligent pigging of flowlines should be conducted. The frequent pipeline rupture within the operational areas of $\mathrm{E} \& \mathrm{P}$ companies in Nigeria is an Fig 10. Surveillance for vibration example of pipeline integrity problem that can be minimised through adequate surveillance techniques.

\section{DISCUSSIONS}

The data used for this work were obtained from some $\mathrm{E} \& \mathrm{P}$ companies in Nigeria informally. Consequently, we cannot mention the names of the companies and/or specific fields for legal reasons. Our aim is to subject these data to the surveillance process described in the previous section. The findings are summarized in Tables 1 to 3 . Table 1 shows a typical formation water concentration from a Nigerian oil field. Clearly, such aqueous effluent must be subjected to physical, chemical and biological treatment process before disposal (Uhuegbulam and Dala, 1981). Table 1 also demonstrates that production companies should be concerned with the environmental effects of their effluent discharges.

Table 1 Composition of typical produced formation water

\begin{tabular}{lcc}
\hline Parameter & $\begin{array}{c}\text { Concentration } \\
\text { mg/litre }\end{array}$ & $\begin{array}{c}\text { Recommended level in } \\
\text { Nigeria }^{\mathrm{a}}\end{array}$ \\
Oil \& Grease & 200 & 10 \\
Total suspended solids (TSS) & 73 & 30 \\
Total dissolved solids (TDS) & 110 & 2000 \\
Chlorides & 61 & 600 \\
Total organic carbon (TOC) & 400 & - \\
aSource: FEPA (1991) &
\end{tabular}

Tables 2 and 3 illustrate the output of the surveillance process for wells and flowstation facilities respectively. The four wells and the three flowstations shown in these tables were selected at random from the collected data. Similar outputs can be designed for flowlines. Table 2 indicates that the listed wells have production problems. From Table 3 we observe that flowstation $\mathrm{A}$ and $\mathrm{C}$ exceeded their liquid capacities while flowstations $\mathrm{B}$ and $\mathrm{C}$ exceeded their gas capacities. Capacity constraint could lead to major environmental incidents. For reservoir management reasons, it may be expedient to investigate further causes of HGOR and HBSW rather than closing in as suggested in Table 3. Such investigation may then show that other remedial actions should be taken so as to minimize financial losses. 
Oilfield Production Surveillance...

Table 2 A typical well surveillance output

\begin{tabular}{clllllll}
\hline Well & Reservoir & $\begin{array}{l}\text { Gross } \\
\text { Production } \\
\text { B/D }\end{array}$ & $\begin{array}{l}\text { GOR } \\
\text { SCF/STB }\end{array}$ & $\begin{array}{l}\text { Rsi } \\
\text { SCF/STB }\end{array}$ & $\begin{array}{l}\text { BSW } \\
\%\end{array}$ & $\begin{array}{l}\text { Sand production } \\
\text { lb/Mbbl }\end{array}$ & $\begin{array}{l}\text { Remarks/ } \\
\text { Actions }\end{array}$ \\
1S & B7.0A & 851 & 3200 & 932 & 51 & 2.1 & $\begin{array}{l}\text { HGOR } \\
\text { Bean down } \\
\text { HBSW, GOR } \\
\text { Doubtful } \\
\text { Bean down } \\
\text { HB }\end{array}$ \\
E3.0F & 765 & 200 & 578 & 63 & 1.4 & $\begin{array}{l}\text { HBW, HGOR } \\
\text { Bean down } \\
\text { Monitor Sand cut }\end{array}$ \\
\hline
\end{tabular}

It should be pointed out that pertinent information (gas composition, pour point, well effluent analysis, etc) should be collected and documented during well completion. Such information can act as the baseline data against which subsequent parameters would be compared. If for instance the gas composition indicates that corrosive gases $\left(\mathrm{CO}_{2}, \mathrm{H}_{2} \mathrm{~S}\right.$, etc. $)$ are present, then it would be necessary to monitor corrosion during surveillance. Also, if the crude oil has high pour point (or high wax content) then it would be important to monitor wax deposition. In addition, high salt content would be a good indication of probable scale formation problem during the life span of the well.

Table 3 Typical flowstation facilities surveillance output

\begin{tabular}{|c|c|c|c|c|c|c|}
\hline \multirow[t]{2}{*}{ Flowstation } & \multirow{2}{*}{$\begin{array}{l}\text { Oil } \\
\text { Production } \\
\text { BPD }\end{array}$} & \multicolumn{2}{|c|}{$\begin{array}{c}\text { Liquid Capacity } \\
\text { B/D }\end{array}$} & \multicolumn{2}{|c|}{$\begin{array}{c}\text { Gas Capacity } \\
\text { MMscf/d }\end{array}$} & \multirow[t]{2}{*}{ Action } \\
\hline & & Nominal & Gross & Nominal & Gross & \\
\hline A & 48460 & 60000 & 69634 & 60 & 59.98 & $\begin{array}{l}\text { Choke back, } \\
\text { close in HBSW producing } \\
\text { wells }\end{array}$ \\
\hline B & 14390 & 30000 & 21244 & 30 & 32.25 & $\begin{array}{l}\text { Choke back, } \\
\text { close in HGOR wells }\end{array}$ \\
\hline $\mathrm{C}$ & 40876 & 60000 & 69463 & 60 & 88.69 & $\begin{array}{l}\text { Choke back, } \\
\text { close in on HBSW/ HGOR } \\
\text { producing wells }\end{array}$ \\
\hline
\end{tabular}

The other pertinent question that has not been addressed is how often should surveillance be carried out. Bearing in mind the level of information required to carry out the surveillance process, we would recommend that the monitoring should be on a monthly basis. Shorter frequencies (daily or weekly) will not be feasible. Longer frequencies (quarterly or yearly) may be too long. This is because by the time the report is ready, the problem may have caused irreparable damage to the environment. By using the flowcharts given in this paper as templates, it should be possible to carry out a comprehensive surveillance on a monthly basis

Conclusion: A surveillance process that can be used for proactive diagnosis of production and facility problems, from an environmental point of view, has been presented. The process can be used to identify unfavourable conditions such as gas leaks, corrosivity, and unsafe wells. It is recommended that the frequency of surveillance should be monthly.

\section{REFERENCE}

Ajienka, J. A. (1993): Suggestions on improving well surveillance, Inter Office Memorandum, April 19, PEBE, SPDC-E
Ajienka, J. A. (1995): Prediction of low bean size induced unstable flow in oil wells, PEME 95.39 (March), SPDC-E, Nigeria

Ajienka, J. A. and Kuye, A. (1999): Impact of unsafe wells on the environment: Lessons from Obelle fire incident, Nig. Society of Chem. Engrs. Proceedings, 29, 95-103

Allen, T. O. and Roberts, P. A. (1982): Production Operations Vol 2, Chapter 1, OCGI, Tulsa

FEPA (1991): Guidelines and Standards for environmental pollution control in Nigeria, Federal Environmental Protection Agency, Nigeria

Uhuegbulam, B. S. and Dala, H. N. (1981): handling of production effluents in fresh water environment: The Obagi experience, Proceeding of the Seminar on Petroleum Industry and the Petroleum Industry and the Nigerian Environment, NNPC, Lagos

\section{.NOMENCLATURE}

\begin{tabular}{ll}
\hline B/D & Barrels per day \\
BHP & Bottom hole pressure, psi \\
CMT & Cement \\
F/S & Flow station \\
F/S & Flowstation \\
GLR & Gas liquid ratio, scf/stb \\
GOR & Gas oil ratio, scf/stb \\
\hline
\end{tabular}

AJIENKA, J A; KUYE, A 
Oilfield Production Surveillance...

\begin{tabular}{ll}
\hline HBSW & High basic sediment and water \\
HGOR & High gas oil ratio \\
MSDV & Master Shut Down Valve \\
OWC & Oil water contact, ft \\
$\mathrm{P}_{\mathrm{b}}$ & Bubble point pressure, psi \\
PERF & Perforation of wellbore, ft \\
ppbbl & Pounds per barrel \\
$\mathrm{P}_{\text {res }}$ & Reservoir pressure, psi \\
Rsi & Initial solution gas oil ratio, scf/stb \\
scf & standard cubic feet \\
SSSV & Subsurface safety valve \\
stb & Stock tank barrel \\
TDS & Total dissolved solids \\
TOC & Total organic carbon \\
TSS & Total suspended solids \\
TTSCON & Through Tubing Sand Consolidation \\
W/O & Workover \\
XHP & Extra high pressure \\
\hline
\end{tabular}

AJIENKA, J A; KUYE, $A$ 